\title{
Correlation Between Clarithromycin Resistance, Virulence Factors and Clinical Characteristics of the Disease in Helicobacter pylori Infected Patients in Shahrekord, Southwest Iran"
}

\author{
Razieh Sadat Hosseini \\ Shahrekord University of Medical Science \\ Ghorbanali Rahimian \\ Shahrekord University of Medical Science \\ Mohammad Hadi Shafigh \\ Shahrekord University of Medical Science \\ Majid Validi \\ Shahrekord University of Medical Science \\ Mansoor Khaledi
}

Shahed University Faculty of Medical Sciences

Abolfazl Gholipour ( $\square$ gholipoa@gmail.com )

Shahrekord University of Medical Science https://orcid.org/0000-0001-5125-7920

\section{Research}

Keywords: Helicobacter pylori, Antibiotic resistance, Real-time PCR, Clarithromycin

Posted Date: February 5th, 2021

DOl: https://doi.org/10.21203/rs.3.rs-184554/v1

License: (c) (i) This work is licensed under a Creative Commons Attribution 4.0 International License.

Read Full License 


\section{Abstract}

Background: The purpose of this study was to determine the mutations associatedwith clarithromycin resistance in Helicobacter pylori isolates isolated from biopsy samples that were collected from the endoscopic ward of Shahrekord Hajar teaching Hospital and also to study the frequency of virulence factor and their correlation and pathological findings with clarithromycin resistance during the years 2019-2020. In this cross-sectional descriptive study, 152 patients with Helicobacter pylori infection were considered, and then, two common A2142G and A2143G mutations in the 23SrRNA gene associated with resistance were analyzed by Real-time PCR (Taq man). The presence of vacA, iceA1, iceA2,cagA,babA2, and oipA virulence genes was investigated by PCR and $8 \%$ polyacrylamide gel. Then, data were analyzed using the relevant statistical tests.

Results: In this study, the frequency of Helicobacter pylori was $76 \%$ and the frequency of mutant isolates was $57.2 \%$. The frequencies of $A 2142 \mathrm{G}$ and $\mathrm{A} 2143 \mathrm{G}$ point mutations were $42.1 \%$ and $28.3 \%$. There was a significant correlation among oipA, vacA, and iceA1 virulence factors, type of disease, chronic inflammatory score, and glandular atrophy with the antibiotic resistance to clarithromycin. There was no significant correlation between the age and sex of the patients with antibiotic resistance.

Conclusions: According to the results of this study, It seems that the use of clarithromycin to combat this bacterium should be limited.

\section{Background}

Helicobacter pylori is a gram-negative, microaerophilic, and spiral bacterium identified in 1982 [1]. Helicobacter pylori is recognized as the cause of gastritis, gastrointestinal ulcers (gastric, intestinal ulcers), MALT lymphoma, and non-gastric diseases associated with Helicobacter pylori [2-6]. The outcome of infection with this bacterium depends on several factors such as bacterial isolates, host inflammatory responses, host genetic diversity, and environmental factors [7-10].

The prevalence of Helicobacter pylori varies worldwide [11]. $50 \%$ of the developed countries and $80 \%$ of developing countries are infected by this bacterium[12,13]. As for the prevalence of the bacterium and its related diseases, proper treatment is very important. The antibiotic resistance of this bacterium is progressively increasing and has become a global concern and is also an important factor in determining the outcome of treatment. Standard treatment is a three-stage drug that consists of one acid neutralizer and two antibiotics, clarithromycin, and amoxicillin or metronidazole for 14 days[14]. Unfortunately, nowadays, the success of this treatment is less than $80 \%$ worldwide [15]. Unsuccessful treatment includes a variety of causes including lifestyle habits such as smoking, bacterial isolates, immunodeficiency, antibiotic resistance, and inadequate treatment. Unsuccessful treatment includes a variety of causes like lifestyle habits such as smoking, bacterial isolates, immunodeficiency, antibiotic resistance, and improper treatment $[16,17]$. Unfortunately, the resistance of Helicobacter pylori to these two antibiotics in most of the countries of the world has led to the failure of the first line treatment to 
become a Problem [18]. The most effective treatment regimens in Iranian studies have been recognized to be quadruple regimens based on clarithromycin or furazolidone $[19,20]$. Clarithromycin is a family of macrolides having a bacteriostatic effect, which binds to the peptidyl transferase 23SrRNA subunit of the large subunit of the bacterial ribosome and inhibits the protein-making process [17]. Also, clarithromycin resistance is the result of structural changes in this region. These changes decrease the tendency of the binding of clarithromycin to the target site of the peptidyl transferase ribosomes of the bacterium, and consequently, cause lack of protein inhibition and the main reason for these structural changes is the point mutations in the 23SrRNA region. In fact, resistance to clarithromycin is due to a spontaneous mutation in the chromosome in the $\mathrm{V}$ domain of the 23SrRNA gene. Adenine and guanine displacements have been reported at different points and mostly at the points of A2143G and A2142G, and less at the point of $A 2142 C[16,21]$. A bacterium is very heterogeneous and its virulence varies geographically. Virulence factors help bacteria pathogenic but may determine treatment outcome. Most of the virulence factors examined in $\mathrm{H}$. pylori are cagA and vacA [22]. Studies have been conducted on the correlation between virulence factors and antibiotic resistance worldwide. Because there are contradictory reports from different parts of the world about the relationship between virulence factors and disease type and pathological findings with antibiotic resistance. Also, there has been no study in Iran on the relationship between the presence of virulence factors iopA, vacA, babA2 iceA, and the type of disease and pathological findings with antibiotic resistance. This study aimed to investigate the relationship between resistance to clarithromycin with virulence factors of iceA, vacA, cagA, babA2, oipA, disease type, and pathological findings in Chaharmahal-o- Bakhtiari region of Iran. And based on our knowledge, a significant association between atrophic glandular and degree of inflammation with resistance to clarithromycin has been reported for the first time in this study.

\section{Methods}

\section{Study ethics}

This study was approved by the Ethics Committee of Shahrekord University of Medical Sciences under the code IR.SKUMS.REC.1397.314. The patients included in the study were given the written consent and patient's information questionnaire.

\section{The community understudy}

This study was performed on the symptomatic patients with Helicobacter pylori infection who were referred to endoscopy ward of Hajar Teaching Hospital from January 2019 to May 2020 in Chaharmahal and Bakhtiari Province.

\section{Inclusion criteria include}

1. Having the ability and willingness to participate in the study, 2. People over 15 years of age, 3. Helicobacter pylori infection was confirmed based on biochemical and molecular tests (PCR, RUT) and pathology. Also only the samples that were positive in all 3 methods were included in the study. 


\section{Exclusion criteria included}

1. People taking aspirin or non-steroidal- anti-inflammatory drugs. 2. Those with metabolic disorders and immunosuppression. 3. People who have recently used antibiotics. 4. People younger than 15 years old and pregnant and lactating women were not included in this study.

\section{Sampling}

200 people participated in the study. Gastrointestinal specialist received 3 biopsies from the antrum of suspected Helicobacter pylori that one of them was examined by rapid urease assay and a sample was subjected to pathological examinations and the other one was stored at $-70^{\circ} \mathrm{C}$ until DNA extraction. Then, the DNA was extracted by DNA extraction kit Bioflux (Japan) in terms of the kit instructions. Also, all the extracted DNA were kept in freeze at $-70^{\circ} \mathrm{C}$ until use. Helicobacter pylori infection was confirmed based on biochemical and molecular tests (PCR, RUT) and pathology. Also only the samples that were positive in all 3 methods were included in the study. Among 200 patients, 152 were diagnosed with Helicobacter pylori infection.

\section{Molecular diagnosis}

PCR test to amplify a 16SrRNA gene fragment to confirm the presence of Helicobacter pylori were performed using primers, temperature conditions, and concentration and volume of the proposed material by De Francesco et al [23]. using Astec thermocycler (Japan) on all biopsies. Then, the amplified fragment was visualized using $8 \%$ polyacrylamide gel and stained with silver nitrate. Based on the results of PCR molecular test, RUT test and pathology, 152 samples were confirmed for Helicobacter pylori. These samples were also analyzed by PCR assay for the presence of iceA1, iceA2, vacA, cagA, babA2, and oip $A$ genes using the primers, temperature, concentration, and volume of the materials proposed by Bagheri et al. including 35 cycles of denaturation (at $94^{\circ} \mathrm{C}$ for $30 \mathrm{~s}$ ), annealing (at $58^{\circ} \mathrm{C}$ for $30 \mathrm{~s}$, extension at $72^{\circ} \mathrm{C}$ for $30 \mathrm{~s}$ ), and one final extension (at $72^{\circ} \mathrm{C}$ for $5 \mathrm{~min}$ ). To investigate susceptible and resistant isolates of two common A2142G and A2143G mutations in the 23SrRNA gene related to clarithromycin resistance, Real-Time PCR (Taq man) and primer pairs and probes, temperature, and concentration of De Francesco et al. proposed materials were used. Real-Time-PCR reactions were performed in a total volume of $25 \mu$ l containing $3 \mu \mathrm{l}$ of synthesized DNA solution, $12.5 \mu \mathrm{l}$ of 2x Rotor-Gene Probe PCR Master Mix (Ampliqon, Denmark), $1 \mu \mathrm{l}$ DMSO, $500 \mathrm{nM}$ of each primer, and $250 \mathrm{nM}$ of the TaqMan probe (TAG Copenhagen, Denmark). Amplification program included a pre warming step (5 min at $95^{\circ} \mathrm{C}$ ), denaturation step $\left(95^{\circ} \mathrm{C}\right.$ for $\left.20 \mathrm{~s}\right)$, and an annealing $\left(58^{\circ} \mathrm{C}\right.$ for $\left.20 \mathrm{~s}\right) /$ extension step $\left(72^{\circ} \mathrm{C}\right.$ for $\left.20 \mathrm{~s}\right)$ [24], that were performed in Corbett (Australia).

All reactions were repeated three times and each time positive and negative controls were tested. Also, each mutation was separately examined. All reactions were repeated thrice and each time positive and negative controls were tested. In addition, each mutation was separately examined. Due to the lack of access to standard isolates, several clinical isolates were sequenced.

\section{Statistical analysis}


Statistical analysis was performed using SPSS-18 software for Windows (IBM SPSS statistics, version 16.0.0; SPSS, Chicago, IL, USA). Chi-square test was used to investigate the association between patient and isolate characteristics in Helicobacter pylori clinical isolates with mutations related to clarithromycin resistance. P-value less than 0.05 was considered significant.

\section{Results}

\section{Resistance to clarithromycin}

The clinical and demographic characteristics of the patients are presented in Table.1. Among 200 patients, 152 were diagnosed with Helicobacter pylori infection. That the prevalence rate of Helicobacter pylori is $76 \%$., Among them the frequency of the isolates with mutations was $57.2 \%$ and the percentage of isolates without mutation was $42.8 \%$. In general, the percentage of A2142G1 point mutation was $42.1 \%$, of which $3.3 \%$ had homozygous genotype and $38.8 \%$ had heterozygous genotype. Also, the percentage of $A 2143 \mathrm{G}$ point mutation is $28.3 \%$ that $7.9 \%$ of the isolates had homozygous genotype and $20.4 \%$ of the isolates had heterozygous genotype.Twenty $(13.2 \%)$ isolates showed both $\mathrm{A} 2142 \mathrm{G}$ and A2143G mutations. The most frequent $2142 \mathrm{G}$ mutation was $42.1 \%$.

(Homozygous samples are samples that have mutations in two strands of DNA and Heterozygous samples are samples that have mutations in One strand of DNA)

\section{Virulence factor}

In this study, the frequency of bacterial virulence genes were cagA $105(69.1 \%)$, oipA $77(50.7 \%)$,babA2

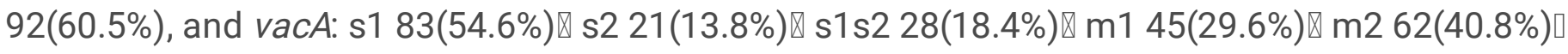
$\mathrm{m} 1 \mathrm{~m} 211(7.2 \%) \rrbracket \mathrm{s} 1 \mathrm{~m} 138(25.0 \%) \rrbracket \mathrm{s} 1 \mathrm{~m} 232(21.1 \%) \square \mathrm{s} 2 \mathrm{~m} 2$ 17(11.2\%) $\square \mathrm{s} 2 \mathrm{~m} 12(1.3 \%) \rrbracket i c e A 156(36.8 \%)$, and iceA2 78(51.3\%), respectively.

\section{Correlation between vacA, cagA, babA2, oipA, iceA1, and iceA2 virulence genes with resistance to clarithromycin}

The correlation among the presence of virulence genes, iceA1, iceA2 vacA, cagA, babA2, and oipA in the studied isolates were investigated as well as the presence of point mutations related to clarithromycin resistance. There was a significant correlation among the presence of oipA (P-Value $=0.033)$, the presence of vacAm1m2, vacATotal $(\mathrm{P}-$ Value $=0.001)$ and vacAs1s2 $(\mathrm{P}-\mathrm{Value}=0.010)$, and the presence of iceA1 $(\mathrm{P}-$ Value $=0.018)$ with antibiotic resistance. Most isolates with virulence genes oipA, vacA, and ice $A 1$ have antibiotic resistance to clarithromycin, as shown in Figure.1.

\section{Correlation between disease type and resistance to clarithromycin}

There was a significant correlation between antibiotic resistance to clarithromycin and the type of disease, in people with gastritis $(P-V a l u e=0.032)$, which is considered as a mild form of Helicobacter 
pylori infection, in which Helicobacter pylori isolates are involved without antibiotic mutation. However, the isolates causing gastrointestinal ulcer are mostly resistant to clarithromycin antibiotics, as shown in Figure.2.

\section{Correlation between age and gender by resistance to clarithromycin}

Patients' age was categorized into three groups (under $30,30-60$, and over 60 years old). The association between that and the sex of the patients with antibiotic resistance was examined; however, no significant correlation was observed between them.

\section{Correlation between pathology findings and claritromycin resistance}

There was a significant correlation between claritromycin resistance and a degree of chronic inflammation (P-Value $=0.000)$. Accordingly, most of the people with mild chronic inflammation have a isolate Helicobacter pylori without mutation, and most of the people with moderate to severe inflammation have mutant isolates. There was also a significant correlation between antibiotic resistance to clarithromycin and glandular atrophy $(P-V a l u e=0.006)$. Most people without glandular atrophy have wild-type or antibiotic-sensitive isolates, and those with glandular atrophy (mild to severe) often have mutant or clarithromycin-resistant isolates, as indicated in Figure.2.

\section{Discussion}

This study aimed to determine the mutations associated with clarithromycin resistance in Helicobacter pylori isolates, and also to investigate its correlation with virulence factors ice $A 1$, ice $A 2, v a c A$, cagA, babA2, and oipA and the type of disease and pathological findings.

In this study, it was found that, clarithromicin resistancewas significantly correlated with some virulence factors, type of disease, and degree of inflammatory. In the present study, the rate of clarithromycin resistance was $57.2 \%$ and the $A 2142 \mathrm{G}$ mutation was recognized as the most common mutation. According to the patients, they have not yet received antibiotic treatment for their infection, therefore should probably be considered as the actual primary resistance.

This resistance rate is higher than in southern European countries like Spain, (32.01\%), and Portugal (42.35\%), that they have the highest resistance to clarithromycin among European countries[25, 26]. Level with some Asian countries such as Korea (60\%), China (52\%), India (58.8\%) and some Northern European countries like Ireland (60.6\%) and parts of the United States like Texas (50\%) [11, 27-29]. Also, according to a 2012 report by Kargar et al, Which reported $35.98 \%$ of clarithromycin resistance in Chaharmahal and Bakhtiari Province [30], it has been shown that the resistance to clarithromycin has increased 1.5-fold over the past nine years. clarithromycin resistance is due to the increased macrolide intake not only in Helicobacter pylori treatment, but also due to increasing in the treatment of respiratory tract infections. 
Also for this reason, rapid and accurate screening of clarithromycin-resistant isolates is clinically important. The failure of first-line treatment due to resistance to this drug has not only chronicled the disease and the increased its other side effects, but has also led to the increased financial burden worldwide and to the limited use of antibiotics in treatment $[19,31]$. In this study, it was found that, there is a significant correlation among virulence factor oipA gene, vacAm1m2, vacATotal, vacAs1s2, and iceA1 gene with antibiotic mutation in relation to clarithromycin $(P=0.033),(P=0.001),(P=0.010)$, and $(P=$ 0.018). The majority of $\operatorname{vacA}$ oipA, and iceA1 positive isolates have mutation and resistance to clarithromycin. In fact, this result confirms the correlation between resistance and the presence of virulence factor iceA1, oipA, and vacA, but no significant correlation was found between clarithromycin resistance and virulence factors $\operatorname{cag} A$ and $b a b A 2$. Studies on the association between virulence factors and antibiotic resistance are very conflicting, So far, no studies have been conducted in Iran on the correlation between the presence of virulence factor oipA, vacA, babA2, and iceA, and antibiotic resistance. The association of these factors with antibiotic resistance was reported for the first time in this study. The current study data on the association of virulence genes oipA, iceA, and vacA with clarithromycin antibiotic resistance are primarily consistent with data from Treiber [32], Karabiber [33], and Boyanova [34], and subsequently, the correlation between the presence of virulence factor and antibiotic resistance regardless of the type of factor the studies support and endorse Khan [35], Brennan [27], and wang [36]. To justify this, it can be said that, isolates with virulence factors, especially oipA, produce inflammatory cytokines like IL-8 and cause aggressive disease like gastrointestinal ulcer. As a result, the patient has painful and uncomfortable symptoms, so starts taking antibiotic drugs that results in a failure in completing the course of treatment, and inadequate use and various other factors make the involved isolate resistant to antibiotics. The results of this study on virulence factors babA2 and cagA showed no significant correlation between the presence of these factors and clarithromycin resistance. This is consistent with the results of studies by Wang [36], Godoy [37], Baglan [38], Broutet [39], and Lõivukene [40]. In this study, there was no significant correlation between age and sex of the patients with clarithromycin resistance. This is in line with the results of Korona [41] and Elviss [42] and contrasts with the results of Wang [36], Chang [43], and Treiber [32]. In this study, a significant relationship was observed between the degree of chronic inflammation and Glandular Atrophy with antibiotic resistance. Frequency of clarithromycin resistance in the patients with moderate to severe chronic inflammation and mild to moderate Glandular Atrophy were different compared with the patients with mild chronic inflammation and those without Glandular Atrophy, based on our knowledge, we are reporting this for the first time.

In this study, there was a significant correlation between antibiotic resistance to clarithromycin and type of disease in the patients infected by Helicobacter pylori $(P=0.032)$. The frequency of clarithromycin resistance was significantly higher in the patients with gastrointestinal ulcer compared to the patients with gastritis. This study is in line with the study of Treiber [32] and contrary to the results of Wang [36], which can be interpreted as isolates that cause an aggressive state of the disease like peptic ulcer. Because of painful and irreversible symptoms, the patient received bacterial and infection treatment. The patient has begun taking antibiotics, and failure to complete the course of treatment, inadequate use, and various other factors have made the isolates involved, resistant to antibiotics. This study was performed 
the first time in Iran investigating the correlation among clarithromycin antibiotic resistance and disease type and pathologic findings in Helicobacter pylori, and reported a significant correlation between these variables.

\section{Conclusions}

Given these results, it is suggested that, the use of different from clarithromycin drugs and regular treatment in the patients with peptic ulcer may be much more necessary than before, because most of the isolates obtained from patients with peptic ulcer are resistant to claritromycin, antimicrobial used in firstline treatments. These results indicate the necessity of determination the antibiotic resistance patterns of H. pylori before prescribing antibiotics, that this would help identify patients who are not suitable for clarithromycin-based therapies.

\section{Abbreviations}

PCR: polymerase chain reaction; vacA: Vacuolating cytotoxin A; cagA: cytotoxin associated genes A; oipA: outer inflammatory protein A; RUT: Rapid urease test; DMSO; Dimethyl sulfoxide; MALT: Mucosaassociated lymphoid tissue.

\section{Declarations}

\section{Acknowledgments}

This study was financially supported by research deputy of Shahrekord University of Medical Sciences. The authors are grateful to the staffs of Cellular \& Molecular Research Center, Shahrekord University of Medical Sciences, and the authorities of the endoscopy unit of Shahrekord Hajar Hospital for their valuable helps. This paper has been derived from the MSc thesis of the first author.

\section{Funding}

This study was financially supported by research deputy of Shahrekord University of Medial Sciences with grant number 2953 .

\section{Availability of data and material}

The datasets used and/or analyzed during the present study are available from the corresponding author on reasonable request.

\section{Ethics approval and consent to participate}

All procedures performed in studies involving human participants were in accordance with the ethical standards of national research committee and with the 1964 Helsinki Declaration and its later amendments or comparable ethical standards. The study was approved by the Ethics Committee of 
Shahrekord University of Medical Sciences under code IR.SKUMS.REC.1397.314 .Informed consent was obtained from all individual participants included in the study.

Consent for publication

The participant has consented to the submission of the case report to the journal.

\section{Conflicts of Interest}

The authors have declared that no competing interests exist. All authors have approved this manuscript.

Authors' contributions

All authors contributed to the study conception and design. Material preparation, data collection and analysis were performed by RSH, AG, MK, GR, MV. The first draft of the manuscript was written by RSH $A G, M K, G R, M H S, M V$. All authors read and approved the final manuscript.

\section{References}

1. Marshall BJ, Warren JR: Unidentified curved bacilli in the stomach of patients with gastritis and peptic ulceration. Lancet (London, England) 1984, 1(8390):1311-1315.

2. Fujikawa A, Shirasaka D, Yamamoto S, Ota H, Yahiro K, Fukada M, Shintani T, Wada A, Aoyama N, Hirayama $T$ et al: Mice deficient in protein tyrosine phosphatase receptor type $Z$ are resistant to gastric ulcer induction by VacA of Helicobacter pylori. Nature genetics 2003, 33(3):375-381.

3. Lee I, Lee H, Kim M, Fukumoto M, Sawada S, Jakate S, Gould VE: Ethnic difference of Helicobacter pylori gastritis: Korean and Japanese gastritis is characterized by male- and antrum-predominant acute foveolitis in comparison with American gastritis. World journal of gastroenterology 2005, 11(1):94-98.

4. Khaledi M, Bagheri N, Validi M, Zamanzad B, Afkhami H, Fathi J, Rahimian G, Gholipour A: Determination of CagA EPIYA motif in Helicobacter pylori strains isolated from patients with digestive disorder. Heliyon 2020, 6(9):e04971.

5. Sanaii A, Shirzad H, Haghighian M, Rahimian G, Soltani A, Shafigh M, Tahmasbi K, Bagheri N: Role of Th22 cells in Helicobacter pylori-related gastritis and peptic ulcer diseases. Molecular biology reports 2019, 46(6):5703-5712.

6. Azadegan-Dehkordi F, Shirzad H, Ahmadi R, Bashash D, Abdollahpour-Alitappeh M, Luzza F, Larussa T, Nahid-Samiei M, Rahimian G, Shafigh M-H: Increased Indoleamine 2, 3-Dioxygenase expression modulates Th1/Th17/Th22 and Treg pathway in humans with Helicobacter Pylori-Infected gastric mucosa. Human Immunology 2020.

7. Montecucco C, de Bernard M: Molecular and cellular mechanisms of action of the vacuolating cytotoxin (VacA) and neutrophil-activating protein (HP-NAP) virulence factors of Helicobacter pylori. Microbes and infection 2003, 5(8):715-721. 
8. Rhead JL, Letley DP, Mohammadi M, Hussein N, Mohagheghi MA, Eshagh Hosseini M, Atherton JC: A new Helicobacter pylori vacuolating cytotoxin determinant, the intermediate region, is associated with gastric cancer. Gastroenterology 2007, 133(3):926-936.

9. Nahid-Samiei M, Rahimian G, Shafigh M, Taheri F, Karami-Hurestani M, Sanaei M-j, Heshmati M, Bagheri N: Enhanced Frequency of CD19+ IL-10+ B Cells in Human Gastric Mucosa Infected by Helicobacter pylori. The American journal of the medical sciences 2020, 359(6):347-353.

10. Sanaei M-J, Shirzad H, Soltani A, Abdollahpour-Alitappeh M, Shafigh M-H, Rahimian G, Mirzaei Y, Bagheri N: Up-regulated CCL18, CCL28 and CXCL13 Expression is Associated with the Risk of Gastritis and Peptic Ulcer Disease in Helicobacter Pylori infection. The American Journal of the Medical Sciences 2020.

11. Thung I, Aramin H, Vavinskaya V, Gupta S, Park JY, Crowe SE, Valasek MA: Review article: the global emergence of Helicobacter pylori antibiotic resistance. Alimentary pharmacology \& therapeutics 2016, 43(4):514-533.

12. Hooi JKY, Lai WY, Ng WK, Suen MMY, Underwood FE, Tanyingoh D, Malfertheiner P, Graham DY, Wong VWS, Wu JCY et al: Global Prevalence of Helicobacter pylori Infection: Systematic Review and MetaAnalysis. Gastroenterology 2017, 153(2):420-429.

13. Khademi F, Poursina F, Hosseini E, Akbari M, Safaei HG: Helicobacter pylori in Iran: A systematic review on the antibiotic resistance. Iranian journal of basic medical sciences 2015, 18(1):2.

14. Sugano K, Tack J, Kuipers EJ, Graham DY, El-Omar EM, Miura S, Haruma K, Asaka M, Uemura N, Malfertheiner P: Kyoto global consensus report on Helicobacter pylori gastritis. Gut 2015, 64(9):13531367.

15. Zhang M: High antibiotic resistance rate: A difficult issue for Helicobacter pylori eradication treatment. World journal of gastroenterology 2015, 21(48):13432-13437.

16. Malekzadeh R, Derakhshan MH, Malekzadeh Z: Gastric cancer in Iran: epidemiology and risk factors. Archives of Iranian medicine 2009, 12(6):576-583.

17. Sanches BS, Martins GM, Lima K, Cota B, Moretzsohn LD, Ribeiro LT, Breyer HP, Maguilnik I, Maia AB, Rezende-Filho J: Detection of Helicobacter pylori resistance to clarithromycin and fluoroquinolones in Brazil: a national survey. World journal of gastroenterology 2016, 22(33):7587.

18. Ji Z, Han F, Meng F, Tu M, Yang N, Zhang J: The Association of Age and Antibiotic Resistance of Helicobacter Pylori: A Study in Jiaxing City, Zhejiang Province, China. Medicine 2016, 95(8):e2831.

19. Roghani HS, Massarrat S, Pahlewanzadeh MR, Dashti M: Effect of two different doses of metronidazole and tetracycline in bismuth triple therapy on eradication of Helicobacter pylori and its resistant strains. European journal of gastroenterology \& hepatology 1999, 11(7):709-712.

20. Malekzadeh R, Setodeh R, Amini M, Vakili A, Ansari R, Massarat S: Effect of furazolidone, bismuth subcitrate and amoxicillin on eradication of Helicobacter pylori (HP) in Iran. In: Gastroenterology: 1997. WB SAUNDERS CO-ELSEVIER INC 1600 JOHN F KENNEDY BOULEVARD, STE 1800 ...: A208A208. 
21. Ghotaslou R, Leylabadlo HE, AsI YM: Prevalence of antibiotic resistance in Helicobacter pylori: A recent literature review. World journal of methodology 2015, 5(3):164-174.

22. Taneike I, Nami A, O'Connor A, Fitzgerald N, Murphy P, Qasim A, O'Connor H, O'Morain C: Analysis of drug resistance and virulence-factor genotype of Irish Helicobacter pylori strains: is there any relationship between resistance to metronidazole and cagA status? Alimentary pharmacology \& therapeutics 2009, 30(7):784-790.

23. De Francesco V, Zullo A, lerardi E, Giorgio F, Perna F, Hassan C, Morini S, Panella C, Vaira D: Phenotypic and genotypic Helicobacter pylori clarithromycin resistance and therapeutic outcome: benefits and limits. The Journal of antimicrobial chemotherapy 2010, 65(2):327-332.

24. Bagheri N, Taghikhani A, Rahimian G, Salimzadeh L, Azadegan Dehkordi F, Zandi F, Chaleshtori MH, Rafieian-Kopaei M, Shirzad H: Association between virulence factors of helicobacter pylori and gastric mucosal interleukin-18 mRNA expression in dyspeptic patients. Microbial pathogenesis 2013, 65:7-13.

25. Molina-Infante J, Romano M, Fernandez-Bermejo M, Federico A, Gravina AG, Pozzati L, GarciaAbadia E, Vinagre-Rodriguez G, Martinez-Alcala C, Hernandez-Alonso M: Optimized nonbismuth quadruple therapies cure most patients with Helicobacter pylori infection in populations with high rates of antibiotic resistance. Gastroenterology 2013, 145(1):121-128. e121.

26. Almeida N, Romãozinho J, Donato M, Luxo C, Cardoso O, Cipriano M, Marinho C, Fernandes A, Calhau C, Sofia C: Helicobacter pylori antimicrobial resistance rates in the central region of Portugal. Clinical Microbiology and Infection 2014, 20(11):1127-1133.

27. Brennan DE, Dowd C, O'Morain C, McNamara D, Smith SM: Can bacterial virulence factors predict antibiotic resistant Helicobacter pylori infection? World journal of gastroenterology 2018, 24(9):971981.

28. Mitui M, Patel A, Leos NK, Doern CD, Park JY: Novel Helicobacter pylori sequencing test identifies high rate of clarithromycin resistance. Journal of pediatric gastroenterology and nutrition 2014, 59(1):6-9.

29. Pandya H, Agravat HH, Patel J, Sodagar N: Emerging antimicrobial resistance pattern of Helicobacter pylori in central Gujarat. Indian journal of medical microbiology 2014, 32(4):408.

30. Kargar M, Ghorbani-Dalini S, Doosti A, Souod N: Real-Time PCR Assay Using Allele-Specific TaqMan probe for Detection of Clarithromycin Resistance and Its Point Mutations in Helicobacter Pylori. Journal of Isfahan Medical School 2011, 29(126).

31. Goudarzi M, Heidary M, Azad M, Fazeli M, Goudarzi H: Evaluation of antimicrobial susceptibility and integron carriage in Helicobacter pylori isolates from patients. Gastroenterology and hepatology from bed to bench 2016, 9(Suppl1):S47-s52.

32. Treiber G, Wittig J, Ammon S, Walker S, van Doorn LJ, Klotz U: Clinical outcome and influencing factors of a new short-term quadruple therapy for Helicobacter pylori eradication: a randomized controlled trial (MACLOR study). Archives of internal medicine 2002, 162(2):153-160. 
33. Karabiber $\mathrm{H}$, Selimoglu MA, Otlu B, Yildirim O, Ozer A: Virulence factors and antibiotic resistance in children with Helicobacter pylori gastritis. Journal of pediatric gastroenterology and nutrition 2014, 58(5):608-612.

34. Boyanova L, Yordanov D, Gergova G, Markovska R, Mitov I: Association of iceA and babA genotypes in Helicobacter pylori strains with patient and strain characteristics. Antonie van Leeuwenhoek 2010, 98(3):343-350.

35. Khan A, Farooqui A, Manzoor H, Akhtar SS, Quraishy MS, Kazmi SU: Antibiotic resistance and cagA gene correlation: a looming crisis of Helicobacter pylori. World journal of gastroenterology 2012, 18(18):2245-2252.

36. Wang D, Guo Q, Yuan Y, Gong Y: The antibiotic resistance of Helicobacter pylori to five antibiotics and influencing factors in an area of China with a high risk of gastric cancer. BMC microbiology 2019, 19(1):152.

37. Godoy APO, Ribeiro ML, Benvengo YHB, Vitiello L, Miranda MdCB, Mendonça S, Pedrazzoli J: Analysis of antimicrobial susceptibility and virulence factors in Helicobacter pyloriclinical isolates. BMC gastroenterology 2003, 3(1):20.

38. Baglan PH, Bozdayi G, Ozkan M, Ahmed K, Bozdayi AM, Ozden A: Clarithromycin resistance prevalence and Icea gene status in Helicobacter Pylori clinical isolates in Turkish patients with duodenal ulcer and functional dyspepsia. Journal of microbiology (Seoul, Korea) 2006, 44(4):409416.

39. Broutet N, Marais A, Lamouliatte H, de Mascarel A, Samoyeau R, Salamon R, Megraud F: cagA Status and eradication treatment outcome of anti-Helicobacter pylori triple therapies in patients with nonulcer dyspepsia. Journal of clinical microbiology 2001, 39(4):1319-1322.

40. Loivukene K, Kolk H, Maaroos HI, Kasenomm P, Ustav M, Mikelsaar M: Metronidazole and clarithromycin susceptibility and the subtypes of vacA of Helicobacter pylori isolates in Estonia. Scandinavian journal of infectious diseases 2000, 32(1):59-62.

41. Korona-Glowniak I, Cichoz-Lach H, Siwiec R, Andrzejczuk S, Glowniak A, Matras P, Malm A: Antibiotic Resistance and Genotypes of Helicobacter pylori Strains in Patients with Gastroduodenal Disease in Southeast Poland. Journal of clinical medicine 2019, 8(7).

42. Elviss NC, Owen RJ, Xerry J, Walker AM, Davies K: Helicobacter pylori antibiotic resistance patterns and genotypes in adult dyspeptic patients from a regional population in North Wales. The Journal of antimicrobial chemotherapy 2004, 54(2):435-440.

43. Chang YW, Ko WJ, Oh CH, Park YM, Oh SJ, Moon JR, Cho JH, Kim JW, Jang JY: Clarithromycin resistance and female gender affect Helicobacter pylori eradication failure in chronic gastritis. The Korean journal of internal medicine 2019, 34(5):1022-1029.

\section{Table}


Table 1

Characteristics of the 152 patients infected with Helicobacter pylori"

\begin{tabular}{|lll|}
\hline Variable & & $\mathbf{N}(\%)$ \\
\hline Gender & Male & $74(48.7)$ \\
& Female & $78(51.3)$ \\
\hline Age grupe & Under30 & $11(7.2)$ \\
& $30-60$ & $98(64.5)$ \\
& Upper60 & $43(28.3)$ \\
\hline Histology findings & Chroniclnflammatory & $152(100)$ \\
& Acute Inflammatory & $123(80.9)$ \\
& Lymphoid follicle & $25(16.4)$ \\
& Intestinal metaplasia & $12(7.9)$ \\
& Glandular Atrophy & $74(48.6)$ \\
\hline Endoscopic findings & Gastritis & $90(59.2)$ \\
& Peptic Ulcer & $62(40.8)$ \\
\hline
\end{tabular}

Figures 

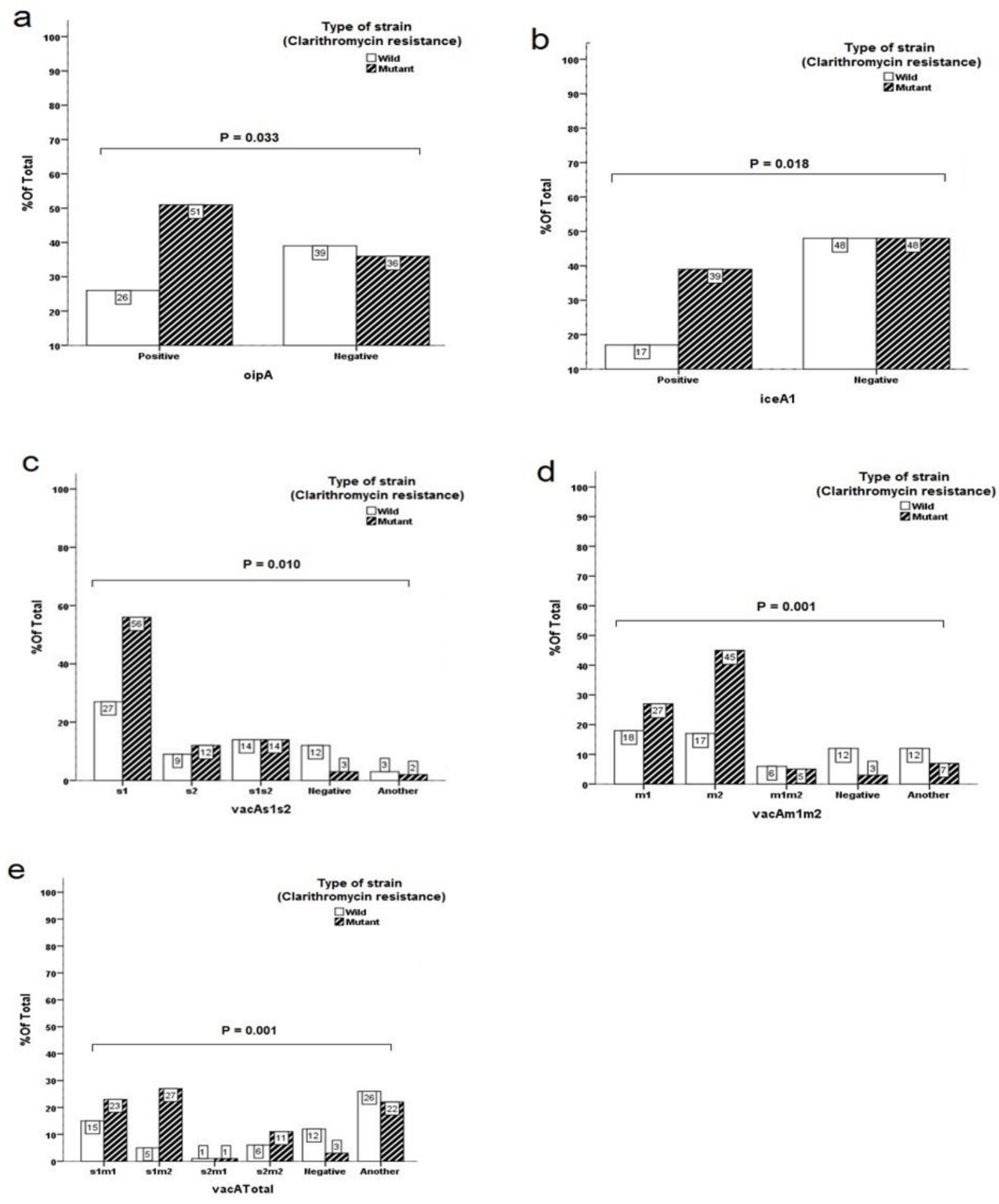

\section{Figure 1}

Correlation between the presence of virulence genes, oipA (a), iceA1 (b), vacAs1s2 (c), vacAm1m2 (d), vacATotal (e) and antibiotic resistance. 

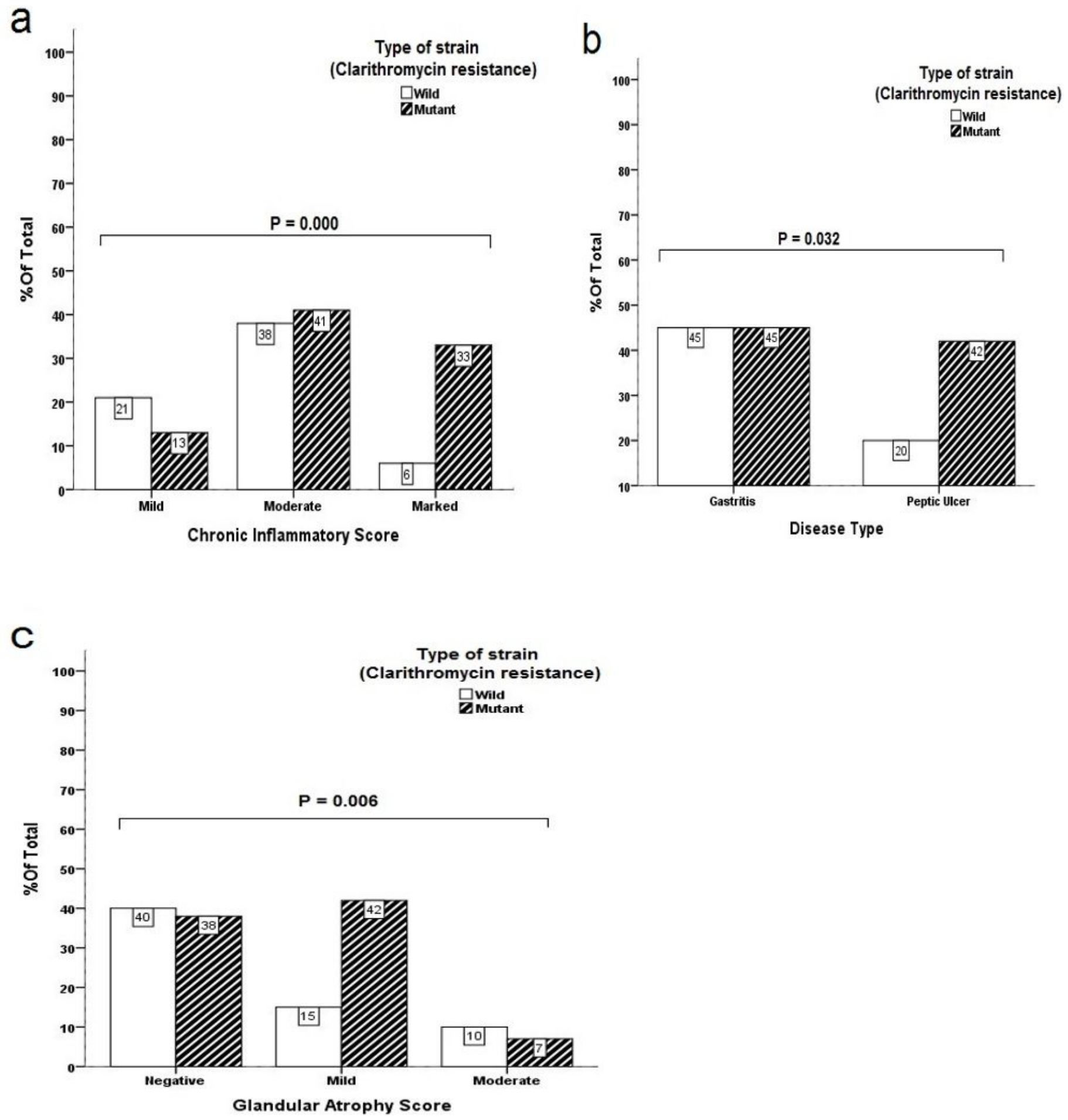

Figure 2

Correlation among the degree of inflammation (a), disease type (b), and Glandular atrophy (c) with the type of strain in terms of clarithromycin resistance. 